OPEN ACCESS

Edited by:

Wen-Lung Ma,

China Medical University, Taiwan

Reviewed by:

Jozsef Dudas,

Innsbruck Medical University, Austria

Jing Xu,

Zhejiang University, China

*Correspondence:

Renfeng $L$

fcchuangs@zzu.edu.cn

${ }^{\dagger}$ These authors have contributed equally to this work

Specialty section:

This article was submitted to Gastrointestinal Cancers: Hepato

Pancreatic Biliary Cancers,

a section of the journal

Frontiers in Oncology

Received: 21 August 2021 Accepted: 09 December 2021

Published: 20 January 2022

Citation:

Huang S, Zhang X, Luo K, Jiang L,

Jiang J and Li R (2022) OxysterolBinding Protein 2 Promotes Pancreatic

Ductal Adenocarcinoma Progression

Through Epithelial-Mesenchymal

Transition.

Front. Oncol. 11:762233.

doi: 10.3389/fonc.2021.762233

\section{Oxysterol-Binding Protein 2 Promotes Pancreatic Ductal Adenocarcinoma Progression Through Epithelial- Mesenchymal Transition}

\author{
Shuai Huang ${ }^{1 \dagger}$, Xudong Zhang ${ }^{1 \dagger}$, Kai Luo ${ }^{1 \dagger}$, Li Jiang ${ }^{2 \dagger}$, Jianhua Jiang ${ }^{3}$ and Renfeng $\mathrm{Li}^{1 *}$ \\ ${ }^{1}$ Departments of Hepatobiliary and Pancreatic Surgery, The First Affiliated Hospital of Zhengzhou University, Zhengzhou, China, \\ 2 Department of Radiotherapy, The First Affiliated Hospital of Zhengzhou University, Zhengzhou, China, ${ }^{3}$ Department of General \\ Surgery, Hua County People's Hospital, Anyang, China
}

Oxysterol-binding protein 2 (OSBP2) is crucial for promoting the growth and development of cancers; however, its effects on pancreatic ductal adenocarcinoma (PDAC) are still unclear. Here, we report that OSBP2 is an efficient tumor-associated protein to lead to extremely malignant characteristics in PDAC. We discovered that increased OSBP2 expression in primary tumors was associated with shorter survival in PDAC patients. Therefore, we used immunohistochemistry $(\mathrm{IHC})$ to analyze the levels of OSBP2 expression in PDAC tissues and adjacent paracancerous tissues. We used wound healing and Transwell assays to evaluate the effects of OSBP2 on PDAC cell (ASPC-1 and BXPC-3) migration and invasion, respectively, and CCK-8 and Annexin V/PI double staining to evaluate the effects of OSBP2 on PDAC cell proliferation and apoptosis, respectively. Western blotting was used to analyze the effect of OSBP2 on the PDAC cell phenotype. We also explored the effect of OSBP2 on chemosensitivity to gemcitabine (GEM) and 5-fluorouracil (5-FU). We validated these findings in an in vivo mouse model. The data show that OSBP2 overexpression promoted PDAC cell migration, invasion, proliferation and chemotherapy resistance, and decreased apoptosis. OSBP2 overexpression downregulated $\mathrm{E}$-cadherin expression and upregulated $\mathrm{N}$-cadherin, vimentin, Snail, Slug, ZEB1, and $\beta$-catenin expression. Taken together, our findings indicated that OSBP2 was overexpressed in PDAC and that upregulation of OSBP2 may promote PDAC progression. Therefore, OSBP2 may have potential diagnostic and therapeutic value in PDAC.

Keywords: epithelial-mesenchymal transition, oxysterol-binding protein 2, pancreatic ductal adenocarcinoma, migration, invasion, proliferation, apoptosis 


\section{INTRODUCTION}

Pancreatic ductal adenocarcinoma (PDAC) is a serious health problem worldwide owing to its poor prognosis, five-year survival rate of less than $5 \%$, and ranks as the eighth most common cause of cancer-related deaths globally (1-3). In China, the median survival of PDAC patients is 7.8 months, with $30.0 \%$ of patients undergoing effective radical resection and $9.8 \%$ of patients undergoing synthetic curative treatment $(4,5)$. However, the causes of PDAC remain unclear. Although tremendous efforts have been made and there has been great progress in this field over the last few decades, PDAC patient survival has not exhibited obvious improvement $(6,7)$. Its aggressive biological phenotype that elicits early local invasion and metastasis features causes low survival rates $(8,9)$. Therefore, we need to further elucidate the molecular mechanisms behind the occurrence, development, treatment resistance and metastasis of this deadly disease.

Cancer cell invasion and metastasis are very complex processes that involve many factors, and the extracellular matrix plays essential roles in the initiation and maintenance of tumor metastasis (10-12). The most critical relevant mechanism mediating the metastatic cascade is the epithelialmesenchymal transition (EMT) process in cancer cells, which is also a primary step in the induction of tumor cell migration and invasion $(13,14)$. EMT plays important roles in embryonic development and the differentiation of multiple tissues and organs and also in the metastasis of cancer cells (15-17). This process is characterized by a loss of cell-to-cell or extracellular matrix adhesions via inhibition of epithelial markers, namely, E-cadherin, and acquisition of mesenchymal features, such as upregulated expression of the mesenchymal markers $\mathrm{N}$-cadherin and vimentin $(18,19)$. Cells undergoing EMT are endowed with increased migratory and invasive properties (20), and a large number of studies have demonstrated that EMT is involved in the development and progression of PDAC (21-23).

The oxysterol-binding protein (OSBP) and OSBP-related protein (ORP) family comprises twelve mammalian genes, and its members are characterized by a conserved OSBP homology domain (OHD) that binds sterols and lipids, a pleckstrin homology $(\mathrm{PH})$ domain and two phenylalanine residues in an acidic tract (FFAT) motif that mediates interactions with the membranes of organelles (24). A great number of studies have demonstrated that some OSBP/ORP members participate in cancer progression, but how OSBP/ORP family members influence cancer cell initiation and progression and the mechanism behind these processes remain unclear. OSBP2, which is also named ORP4, is expressed in the human brain, heart, and testis but not in other human tissues or mouse tissues $(25,26)$. ORP4 plays an important role in human malignant tumor cell proliferation and survival (27) and is a target of the natural antiproliferative steroidal saponin OSW-1 (28), and published studies show that OSBP2 plays a critical role in the control of oncogenic cell growth. At present, no evidence has identified a relationship between PDAC and OSBP2.

This study is the first to demonstrate that OSBP2 may work as a tumor-associated protein that significantly affects the malignant behaviors of PDAC. These behaviors could be significantly enhanced when OSBP2 was overexpressed, while downregulation of OSBP2 decreased the migration and invasion abilities of PDAC cells in vitro and in vivo. Additionally, we showed that OSBP2 was involved in the EMT process of PDAC.

\section{MATERIALS AND METHODS}

\section{Cell Culture and Reagents}

We purchased the human PDAC cell lines ASPC-1 and BXPC-3 from American Type Culture Collection (ATCC) and cultured them in complete growth medium according to the manufacturer's instructions. Cells were maintained in an incubator at $37^{\circ} \mathrm{C}$ and $5 \% \mathrm{CO}_{2}$ and tested for mycoplasma every 3 months (last verified negative date, May 1, 2020). The experiments in this study used cells within ten passages after thawing.

The following reagents were used. RPMI 1640 cell culture medium was purchased from Gibco. Fetal bovine serum (FBS) was obtained from Biological Industries. Pancreatic enzyme and EDTA were acquired from Sigma. Phosphate-buffered saline (PBS) was from DHeLix.

\section{Tissue Specimens}

We obtained 100 PDAC specimens from patients who underwent pancreatic surgical resection and provided informed consent before undergoing surgery. None of the patients received radiotherapy or chemotherapy before surgery. The resected specimens were immediately frozen at $-80^{\circ} \mathrm{C}$, after which tumor and adjacent nontumor tissues were sampled (approximately $1 \mathrm{~cm}^{3}$ of each) and pathologically examined to confirm the patient diagnosis. This study was approved by the Ethics Committee of The First Affiliated Hospital of Zhengzhou University and authorized by Zhengzhou University.

\section{OSBP2 Knockdown and Overexpression in PDAC Cells}

We cloned full-length human OSBP2 cDNA into the pcDNA3.1 plasmid (Invitrogen Co., Ltd. China) to induce stable OSBP2 expression, and Jima Genomics Co., Ltd. designed the siRNAs targeting OSBP2 (siRNA-OSBP2) to knock down OSBP2 expression. In short, cells were seeded at a density of $5 \times 10^{5}$ cells/well in 6-well plates in medium containing $10 \%$ FBS. When the cells reached $80 \%$ confluency, they were transfected with 50 $\mathrm{nmol} / \mathrm{L}$ siRNAs in Lipofectamine 3000 (Invitrogen Co., Ltd. China) for $48 \mathrm{~h}$. Stably transfected cells were selected by Puromycin for 7-14 days, and we used western blotting to evaluate the level of OSBP2 expression. Details are presented in Figure 8. The experiment was repeated three times.

\section{Mouse Strains}

We obtained female BALB/c nude mice and NOD/SCID mice from the Laboratory Animal Centre of Zhengzhou University. Procedures relating to the care and use of mice in this study were conducted in accordance with the National Institutes of Health 
(NIH) guidelines, with the animals housed in an accredited laboratory animal care facility. All animal studies were carried out in accordance with approved Institutional Care and Use Committee protocols at Zhengzhou University.

\section{In Vivo Subcutaneous Injection}

Female BALB/c nude mice aged 4 to 6 weeks were maintained in a barrier facility on high-efficiency particulate air-filtered racks. Twenty mice were divided into four groups ( 5 mice/group) that were injected with the following cell types ( $10^{7}$ cells/injection): OSBP2-knockdown ASPC-1 cells, control ASPC-1 cells, OSBP2-overexpressing BXPC-3 cells, and control BXPC-3 cells. The cells were subcutaneously injected into the right posterior back of the nude mice. Tumor nodules were observed weekly, and the length of the tumor was measured. Four weeks later, all tumor nodules were collected and fixed with $4 \%$ paraformaldehyde for subsequent experiments.

\section{In Vivo Caudal Vein Injection}

Female NOD/SCID mice aged 3 to 4 weeks were maintained in a barrier facility on high-efficiency particulate air-filtered racks. Twenty mice were divided into four groups ( 5 mice/group) that were injected with the following cell types $\left(10^{7}\right.$ cells/injection): OSBP2-knockdown ASPC-1 cells, control ASPC-1 cells, OSBP2overexpressing BXPC-3 cells and control BXPC-3 cells. The cells were injected via tail vein and observed for 8 weeks. Eight weeks later, all of the mice were sacrificed, lung tissues were removed, and the wet weight of both lungs was measured before they were fixed with $4 \%$ paraformaldehyde for subsequent experiments.

\section{Western Blot}

We extracted total proteins from cells and tissue by using RIPA lysis buffer with $1 \%$ phenylmethanesulfonyl fluoride and quantified the protein concentration using a bicinchoninic acid protein assay kit (Wanleibio Co., Ltd., China). We used sodium dodecyl sulfate-polyacrylamide gel electrophoresis (SDS-PAGE) to denature and separate $20 \mu \mathrm{g}$ of protein per sample. Then, the proteins were transferred onto polyvinylidene difluoride membranes (EMD Millipore, Billerica, MA, USA), which were blocked in 5\% skim milk powder (Yili Co., Ltd., China) in Trisbuffered saline-Tween-20 (TBS-T). Then, we incubated the membranes with the corresponding primary antibody overnight at $4^{\circ} \mathrm{C}$, rinsed them 4 times with TBS-T for 5 min per wash, and incubated them with horseradish peroxidase-conjugated secondary antibody for $45 \mathrm{~min}$ at $37^{\circ} \mathrm{C}$. The secondary antibody is goat anti-rabbit IgG-HRP anti-bodies (Wanleibio Co., Ltd., China). The membranes were treated with an enhanced chemiluminescence (ECL) reagent (EMD Millipore) to develop the protein bands. Antibodies targeting the proteins E-cadherin (cat. no. 3195), N-cadherin (cat. no. 13116), Vimentin (cat. no. 5741), Snail (cat. no. 3897), $\beta$-catenin (cat. no. 8480), Slug (cat. no. 9585), and ZEB1 (cat. no. 3396) were purchased from Cell Signaling Technology, Inc. (Danvers, MA, USA). Antibody targeting $\beta$-actin was purchased from Wanleibio. All antibodies were used in accordance with the manufacturer's instructions. The primary antibodies were diluted at a ratio of 1:1,000, and the secondary antibodies were diluted at a ratio of 1:5,000 according to the manufacturer's instructions.

\section{Proliferation Assay}

Different cell lines (ASPC-1, OSBP2-knockdown ASPC-1; BXPC-3, OSBP2-overexpressing BXPC-3) were cultured until they reached approximately $90 \%$ confluence, after which they were washed once with PBS (DHeLix Co., Ltd., China). Then, we added an appropriate volume of $0.25 \%$ trypsin (Sigma Co., Ltd., USA) to disrupt the cell from the culture plates, and when the cells became round, complete medium was added to terminate the reaction. Next, we agitated the cells in the cell culture plate with a $5 \mathrm{ml}$ pipettor, collected the suspension into a $15 \mathrm{ml}$ test tube, and centrifuged the suspension at $88 g$ for $3 \mathrm{~min}$. The supernatant was removed, $1 \mathrm{ml}$ of complete medium was added, and the cells were counted. Cells were seeded into 96-well plates $\left(5 \times 10^{3}\right.$ cells/well) according to the experimental groups. Then, the CCK-8 test was performed after cells were cultured in an incubator at $37^{\circ} \mathrm{C}$ with $5 \% \mathrm{CO}_{2}$ for $0,24,48$, and $72 \mathrm{~h}$. At the indicated times, the supernatant was discarded, $100 \mu \mathrm{l}$ of complete medium and $10 \mu \mathrm{l}$ of CCK- 8 were added to each well, and the cells were cultured in an incubator at $37^{\circ} \mathrm{C}$ with $5 \%$ $\mathrm{CO}_{2}$ for an additional $2 \mathrm{~h}$. The optical density (OD) value at 450 $\mathrm{nm}$ in each well was measured on a standard microplate reader (BIOTEK Co., Ltd., USA).

\section{Cytotoxicity Assay}

Cells were seeded at low density (5,000 cells per well) in 96-well plates and treated with different concentrations $(0-2,000 \mu \mathrm{mol} / \mathrm{l})$ of 5-fluorouracil (5-FU) or gemcitabine (GEM). After $72 \mathrm{~h}$ of incubation, we used the CCK- 8 test to measure the OD value at $450 \mathrm{~nm}$, as mentioned above.

\section{Transwell Assay}

We used Transwell chambers (Corning Inc. USA) to evaluate cell migration and invasion. Matrigel (Corning Inc. USA) was applied to the upper surface of the membranes in the invasion assay. Cells suspended in serum-free medium were added to the upper chamber of the Transwell inserts $\left(6 \times 10^{3}\right.$ cells $)$, and $800 \mu \mathrm{l}$ of medium with $30 \%$ FBS was added to the lower chamber. After incubation, the Transwell membranes were washed twice with PBS, fixed with $4 \%$ paraformaldehyde at room temperature for $20 \mathrm{~min}$, stained with $0.5 \%$ crystal violet solution for $5 \mathrm{~min}$, and rinsed with distilled water. The cells that migrated or invaded to the lower chamber were counted under an inverted microscope (Motic Electric Group Co., Ltd., Xiamen, China) at $200 \times$ magnification.

\section{Wound Healing Assay}

Different cell lines (ASPC-1 cells, OSBP2-knockdown ASPC-1 cells, BXPC-3 cells, OSBP2-overexpressing BXPC-3 cells) were cultured until they reached $100 \%$ confluence. Then, the medium was replaced with serum-free medium, and $1 \mu \mathrm{g} / \mathrm{ml}$ mitomycin $\mathrm{C}$ was added to the cells for $1 \mathrm{~h}$, after which the monolayers were scratched with a $200 \mu$ l pipette tip, washed with serum-free medium to remove cellular debris, observed under a microscope and photographed the positions of the cells in the photos were noted in preparation for subsequent photos. The scratched cultures were incubated in serum-free medium in an incubator at $37^{\circ} \mathrm{C}$ and $5 \% \mathrm{CO}_{2}$ for $48 \mathrm{~h}$ and then photographed again. 


\section{Apoptosis Assay}

The Annexin V-FITC/PI Apoptosis Detection kit (BD Biosciences, San Jose, CA, USA) was used to assess apoptosis according to the manufacturer's instructions. In brief, we washed cells in ice-cold PBS and applied Annexin V-FITC and PI solutions to the cells in the dark for $15 \mathrm{~min}$. Next, we used a FACScan flow cytometer to measure apoptosis rates. Finally, we summarized the data as the mean \pm standard error (SD).

\section{Immunohistochemistry (IHC)}

Fixed tissues were sliced into $5 \mu \mathrm{m}$-thick sections. After they were heated to $60^{\circ} \mathrm{C}$ for $2 \mathrm{~h}$, the specimens were deparaffinized using xylene at room temperature and rehydrated in a descending series of ethanol $(95,85$, and 75\%). For IHC staining, endogenous peroxidase activity was blocked by treatment with $3 \%$ hydrogen peroxide for $15 \mathrm{~min}$. Tissues were then stained with primary antibodies for $12 \mathrm{~h}$ at $4^{\circ} \mathrm{C}$ according to the manufacturer's instructions followed by staining with secondary antibodies. The processed sections were observed under a microscope (OLYMPUS Co., Ltd., Japan) at a magnification of $400 \times$ and imaged.

\section{Hematoxylin and Eosin (H\&E) Staining}

Fixed tissues were sliced into $5 \mu \mathrm{m}$-thick sections. After they were heated to $60^{\circ} \mathrm{C}$ for $1 \mathrm{~h}$, the specimens were deparaffinized using xylene at room temperature and rehydrated in a descending series of ethanol $(95,85$, and $75 \%)$. Subsequently, the samples were stained with hematoxylin for $5 \mathrm{~min}$ and eosin for $3 \mathrm{~min}$ at room temperature. Then, after dehydration, the sections were mounted, viewed under a microscope (200x; OLYMPUS Co., Ltd., Japan) and imaged.

\section{Microarray Analysis}

PDAC tissues and adjacent paracancerous tissues for the tissue microarray (TMA) were obtained at the First Affiliated Hospital of Zhengzhou University. First, an experienced pathologist selected the $1 \mathrm{~mm}$-core area; then, we used a TMA Grand Master (3DHISTECH) to drill and place the recipient blocks. Three cores were obtained from each primary tumor, and 1-3 cores were obtained from the metastatic lymph nodes. We coded and randomly placed the cores on the array. Relevant clinical information was extracted from hospital cases. To compare staining intensity and survival, at least two cores with histological scores are required per patient. In the process of tissue staining analysis, the pathologists were blinded to the clinical data.

\section{Statistical Analysis}

We used SPSS 16.0 (IBM) to conduct statistical analysis in this study. The data are presented as the means \pm SD. All in vitro experiments were conducted independently in triplicate. Comparisons between treatment groups were performed by Student's t-test. Statistical analysis was conducted with either Microsoft Excel or Origin Labs. The Kaplan-Meier method was used to compare overall survival (OS) among patients in different groups, and the log-rank test was used to estimate differences in survival. Univariate and multivariate analyses were based on the
Cox proportional hazards regression model. $\mathrm{P}<0.05$ was considered statistically significant.

\section{RESULTS}

\section{Overexpression of OSBP2 is Correlated With Shorter Survival in PDAC}

The relationship between the clinicopathological characteristics of PDAC patients and OSBP2 expression is revealed in Table 1. Our data demonstrated that OSBP2 expression in PDAC tissues were related to nerve invasion $(P<0.05)$ and pathological grading $(P<0.05)$ but were not related to age, sex, lymph node metastasis or AJCC stage. The IHC staining results showed that OSBP2 expression was higher in PDAC tissues than in adjacent paracancerous tissues (Figure 1A). We used Kaplan-Meier curves to analyze the relationship between OSBP2 expression in PDAC and OS of patients. Our data revealed that high OSBP2 expression was related to shorter survival of these patients (Figure 1B). Therefore, we further investigated the effect of OSBP2 expression on the biological behavior of PDAC cells.

\section{OSBP2 Promotes the Migration and Invasion of PDAC Cells}

We studied the role of OSBP2 in PDAC cell mobility by inhibiting OSBP2 expression in ASPC-1 cells using a specific siRNA and performing a wound healing assay. The results revealed that OSBP2 knockdown reduced wound closure compared with that of the control ASPC- 1 cells $(P<0.05$; Figure 2A). We next overexpressed

TABLE 1 | Relationship between the expression level of OSbp2 and the clinicopathological parameters of pancreatic cancer patients.

\begin{tabular}{|c|c|c|c|c|}
\hline \multirow[t]{2}{*}{ Clinical parameters } & \multirow[t]{2}{*}{$\mathbf{N}$} & \multicolumn{2}{|c|}{ OSBP2 expression } & \multirow[t]{2}{*}{$p$-value } \\
\hline & & $\begin{array}{c}\text { High } \\
\text { [n (\%)] }\end{array}$ & $\begin{array}{c}\text { Low } \\
\text { [n (\%)] }\end{array}$ & \\
\hline Sex & & & & 0.284 \\
\hline Male & 63 & $49(77.8)$ & $14(22.2)$ & \\
\hline Female & 37 & $32(86.5)$ & $5(13.5)$ & \\
\hline Age (years) & & & & 0.135 \\
\hline$<60$ & 47 & $41(87.2)$ & $6(12.8)$ & \\
\hline$\geq 60$ & 53 & $40(75.5)$ & $13(24.5)$ & \\
\hline Nerve invasion & & & & 0.011 \\
\hline Yes & 58 & $52(89.7)$ & $6(10.3)$ & \\
\hline No & 42 & $29(69.0)$ & $13(31.0)$ & \\
\hline Pathological grading & & & & 0.018 \\
\hline I & 12 & $6(50.0)$ & $6(50.0)$ & \\
\hline$\|$ & 78 & $66(84.6)$ & $12(15.4)$ & \\
\hline III & 10 & $9(90.0)$ & $1(10.0)$ & \\
\hline AJCC stage & & & & 1.000 \\
\hline$|-| \mid$ & 98 & 79 (80.6) & $19(19.4)$ & \\
\hline III-IV & 2 & $2(100)$ & $0(0)$ & \\
\hline Lymph node metastasis & & & & 0.427 \\
\hline Absent (NO) & 55 & $43(78.2)$ & $12(21.8)$ & \\
\hline Present (N1-3) & 45 & $38(84.4)$ & $7(15,6)$ & \\
\hline
\end{tabular}

All data are expressed as the number of patients (\%). P-values were calculated using SPSS 17.0 using a Chi-square test. P-values $<0.05$ were considered to indicate statistical significance. OSBP2, Oxysterol-binding protein 2; AJCC stage, American cancer Joint Committee stage. 
A

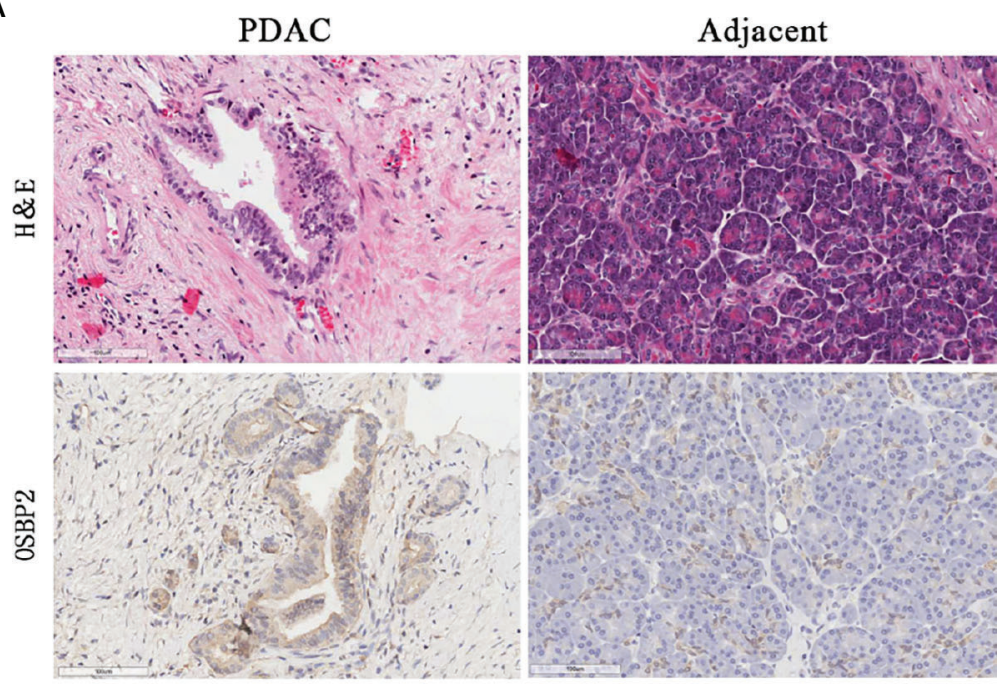

B

OSBP2 survival curve

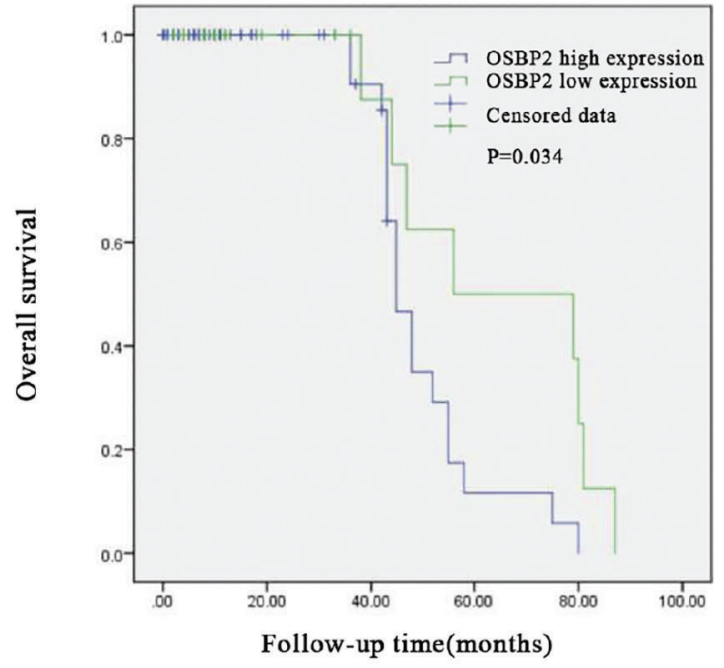

FIGURE 1 | High OSBP2 expression in PDAC correlates with shorter survival. (A) Expression of OSBP2 in pancreatic cancer tissues and paired adjacent paracancerous tissues (Scale bars, $100 \mu \mathrm{m})$. (B) Association between OSBP2 expression in tumors and overall survival in 100 PDAC patients (P = 0.034 by log-rank test). OSBP2, oxysterol-binding protein 2; PDAC, pancreatic ductal adenocarcinoma.

OSBP2 in BXPC-3 cells and performed the wound healing assay, which revealed that OSBP2 overexpression led to increased cell migration compared with empty vector-treated BXPC-3 cells $(P$ $<0.05$; Figure 2B). Transwell assays were employed to further evaluate the impact of OSBP2 on PDAC cell invasion, which showed that PDAC cell invasion was suppressed by OSBP2 inhibition in ASPC-1 cells $(P<0.01$; Figure 2C) and increased by OSBP2 overexpression in BXPC-3 cells $(P<0.01$; Figure 2D).

\section{OSBP2 Decreases the Apoptosis of PDAC Cells}

We investigated the effect of OSBP2 on PDAC cell apoptosis. OSBP2 inhibition significantly increased the number of apoptotic cells and decreased the number of tumor cells compared with those of the control ASPC-1 cells (Figure 3A). By contrast, OSBP2 overexpression dramatically decreased the number of apoptotic cells and increased the number of tumor cells compared with those of empty vector-treated BXPC-3 cells (Figure 3B).

\section{OSBP2 Promotes the Proliferation of PDAC Cells}

We performed a CCK- 8 assay to explore the effect of OSBP2 on PDAC cell proliferation. Our data showed that the OD value of si-OSBP2-infected ASPC-1 cells was lower than that of control ASPC-1 cells at different time points $(P<0.05$; Figure 4A), 
A
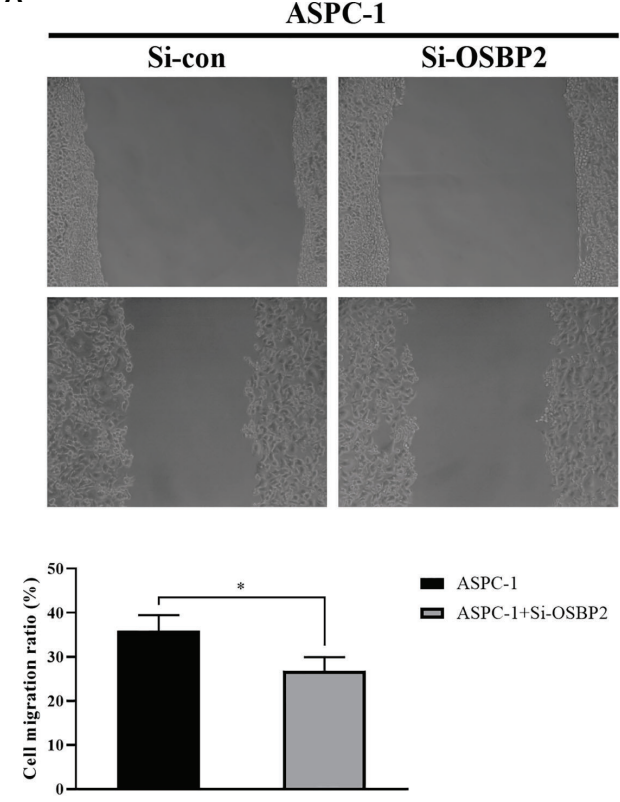

C
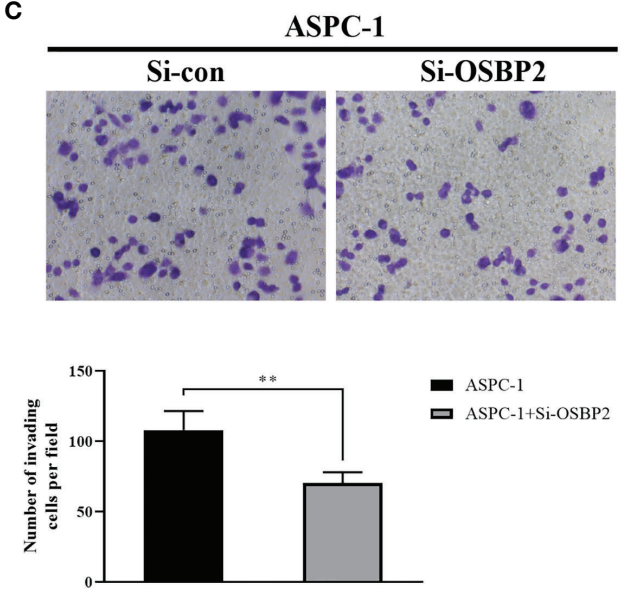

B
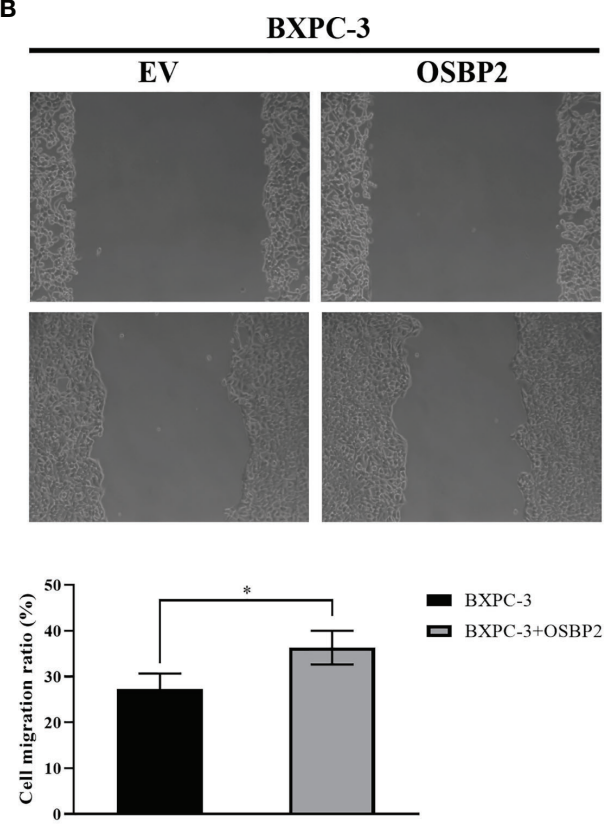

D
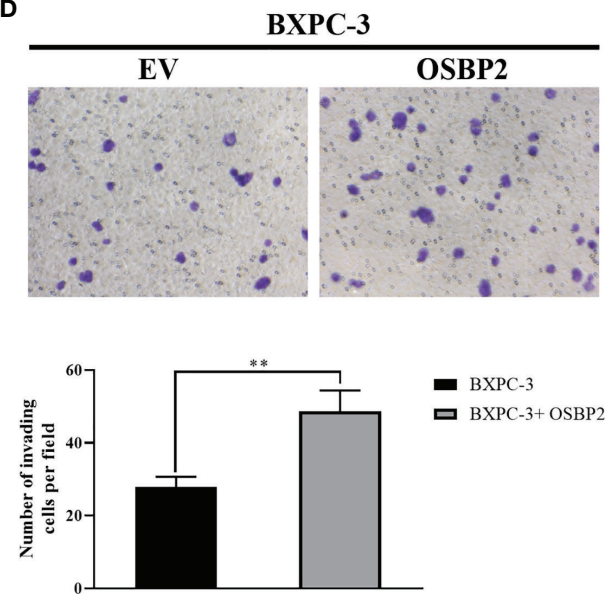

FIGURE 2 | Effect of OSBP2 on PDAC cell migration and invasion. (A) Low OSBP2 expression inhibited ASPC-1 cell migration (P <0.05). (B) Overexpression of OSBP2 promoted BXPC-3 cell migration ( $P<0.05)$. (C) Low OSBP2 expression inhibited ASPC-1 cell invasion $(\mathrm{P}<0.01)$. (D) Overexpression of OSBP2 promoted BXPC-3 cell invasion $(P<0.01)$. OSBP2, oxysterol-binding protein 2; PDAC, pancreatic ductal adenocarcinoma; Si-OSBP2, siRNA targeting OSBP2; $\mathrm{EV}$, empty vector. ${ }^{*} \mathrm{P}<0.05$, ${ }^{* *} \mathrm{P}<0.01$.

whereas the OD value of OSBP2-overexpressing BXPC-3 cells was higher than that of BXPC-3 cells at different time points $(P<0.05$; Figure 4B). This result indicated that OSBP2 inhibition suppressed PDAC cell proliferation in ASPC-1 cells and that OSBP2 overexpression promoted PDAC cell proliferation in BXPC-3 cells.

\section{OSBP2 Increases the Resistance of PDAC Cells to 5-FU and GEM}

Different cell lines (ASPC-1 cells, OSBP2-knockdown ASPC-1 cells, BXPC-3 cells, OSBP2-overexpressing BXPC-3 cells) were exposed to varying concentrations $(0.000,0.010,0.100,1.000$,
$10.000,100.000,1000.000$, and $2000.000 \mu \mathrm{mol} / \mathrm{l})$ of 5 -FU and GEM for $72 \mathrm{~h}$, and the OD values were examined. Our data showed that OSBP2 inhibition decreased the resistance of ASPC-1 cells to 5-FU and GEM, and OSBP2 overexpression increased the resistance of BXPC-3 cells to 5-FU and GEM (Figures 5A, B). As the drug concentration increased, the rate of growth inhibition increased (Figures 5C, D).

\section{OSBP2 Promotes the Proliferation of PDAC Cells In Vivo}

We examined the effect of OSBP2 on tumor growth using transplanted tumor mouse models. To this end, ASPC-1 cells, 
A

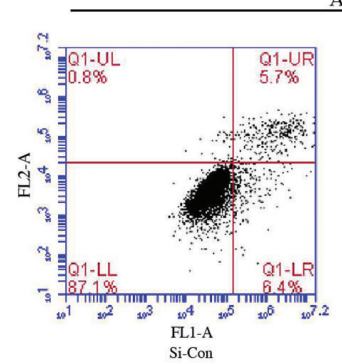

B

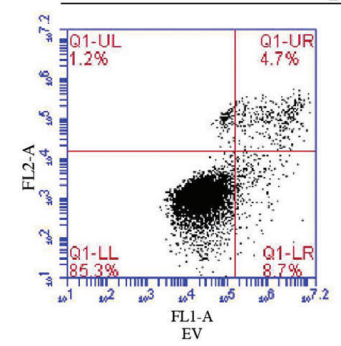

ASPC-1

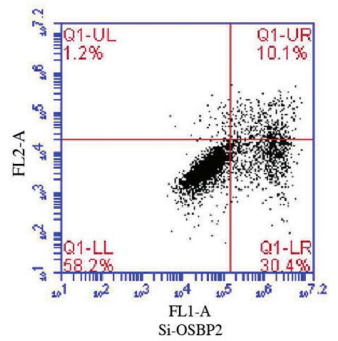

BXPC-3

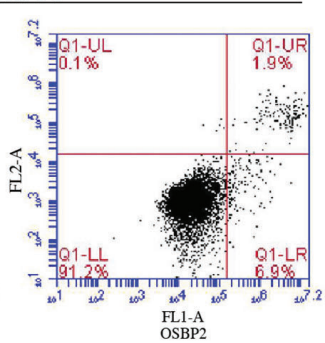

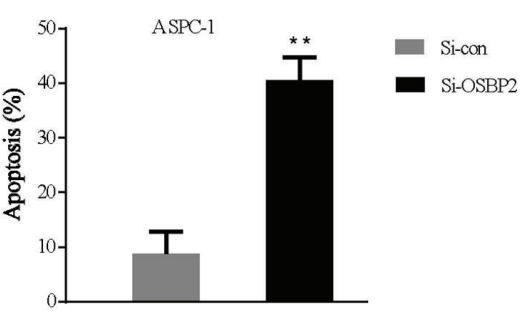

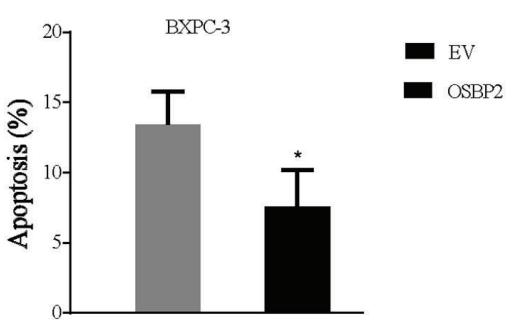

FIGURE 3 | Effect of OSBP2 on PDAC cell apoptosis. (A) Low OSBP2 expression increased tumor cell apoptosis in the ASPC-1 cell line. (B) Overexpression of OSBP2 decreased tumor cell apoptosis in the BXPC-3 cell line. OSBP2, oxysterol-binding protein 2; PDAC, pancreatic ductal adenocarcinoma; Si-OSBP2, siRNA targeting OSBP2; EV, empty vector. ${ }^{\star} \mathrm{P}<0.05{ }^{* *} \mathrm{P}<0.01$.

OSBP2-knockdown ASPC-1 cells, BXPC-3 cells, or OSBP2overexpressing BXPC-3 cells were subcutaneously injected into the right posterior backs of BALB/c nude mice. Four weeks after tumor formation, we removed the tumor nodules and assessed their growth. We observed that OSBP2 inhibition suppressed the growth of ASPC-1-engrafted tumors and that OSBP2 overexpression accelerated the growth of BXPC-3-engrafted tumors (Figure 6A). In agreement with the tumor volumes, the weight of tumors derived from OSBP2-knockdown ASPC-1 cells was significantly lower than that of tumors derived from control ASPC-1 cells, and the weight of tumors derived from OSBP2-overexpression BXPC-3 cells was significantly higher than that of tumors the control $(P<0.05$; Figure 6B). Moreover, we performed H\&E and OSBP2 staining of randomly selected mouse tumors. We observed that OSBP2 inhibition resulted in the downregulation of OSBP2 expression and that OSBP2 promotion resulted in the upregulation of OSBP2 expression (Figures 6C, D).

\section{OSBP2 Promotes the Metastasis of PDAC Cells In Vivo}

We conducted an in vivo metastasis assay by injecting OSBP2knockdown ASPC-1 cells, ASPC-1 cells, BXPC-3 cells, and OSBP2-overexpressing BXPC-3 cells via tail vein into NOD/
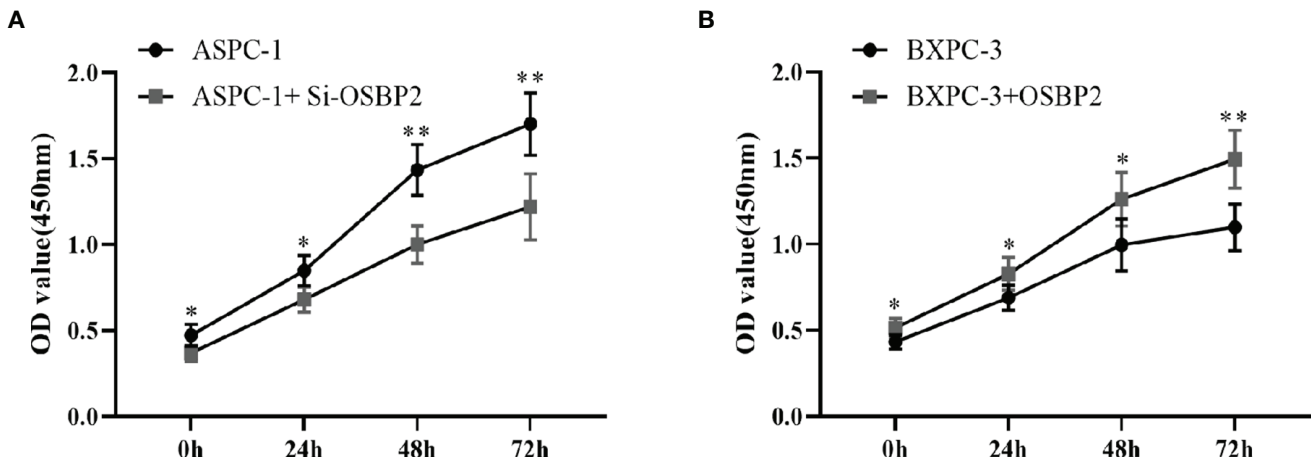

FIGURE 4 | Effect of OSBP2 on PDAC cell proliferation. (A) Low OSBP2 expression decreased tumor cell proliferation in the ASPC-1 cell line (P < 0.01). (B) Overexpression of OSBP2 increased tumor cell proliferation in the BXPC-3 cell line $(\mathrm{P}<0.01)$. OSBP2, oxysterol-binding protein 2; PDAC, pancreatic ductal adenocarcinoma; EV, empty vector. ${ }^{\star} \mathrm{P}<0.05,{ }^{\star \star} \mathrm{P}<0.01$. 
A

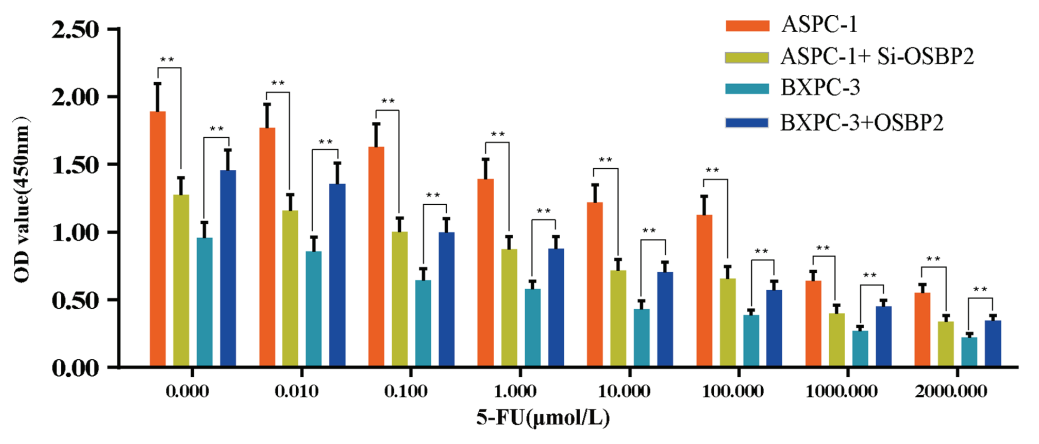

B

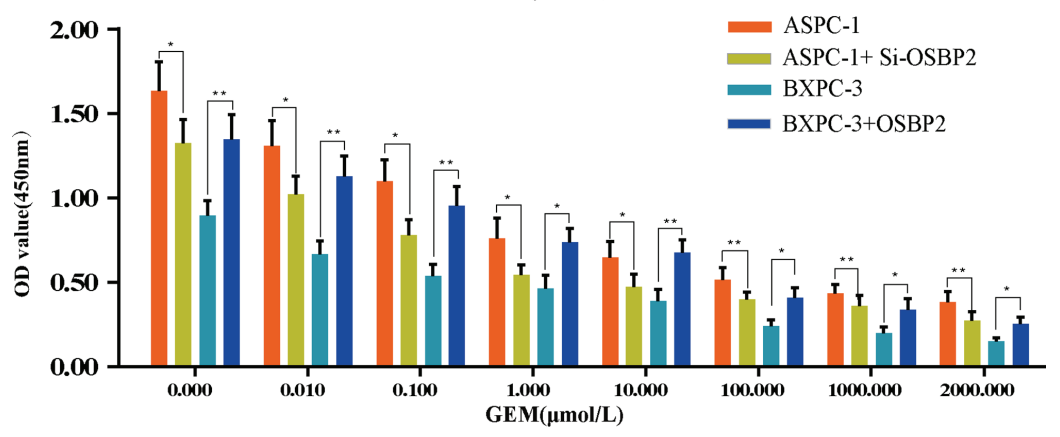

C

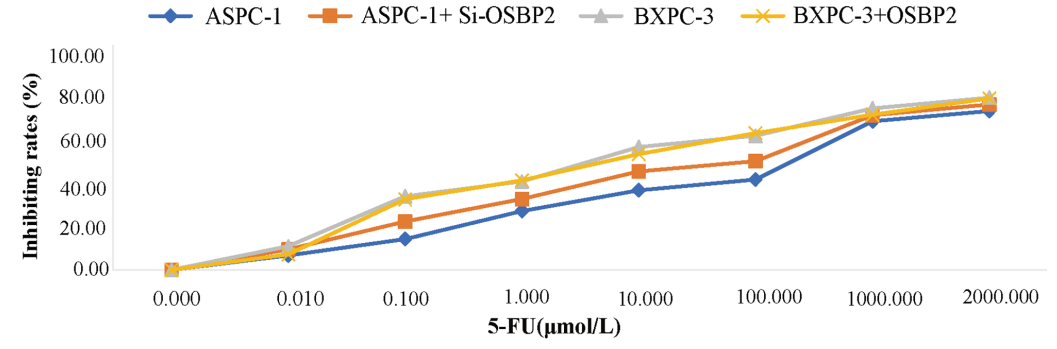

D $\rightarrow$ ASPC-1 $\rightarrow$ ASPC-1+ Si-OSBP2 $\leftarrow$ BXPC-3 $\leftarrow$ BXPC-3+OSBP2

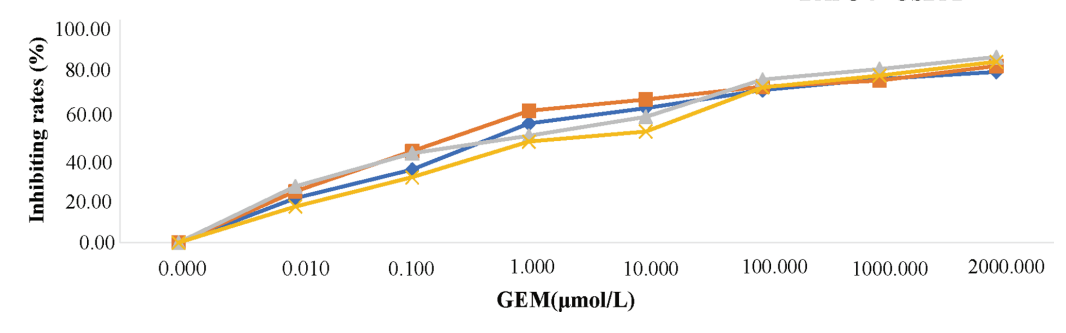

FIGURE 5 | Effect of OSBP2 on the resistance of PDAC cells to 5-FU and GEM. (A) Low OSBP2 expression decreased the resistance of ASPC-1 cells to 5-FU $(P<0.01)$, and OSBP2 overexpression increased the resistance of BXPC-3 cells to 5-FU $(P<0.01)$. (B) Low OSBP2 expression decreased the resistance of ASPC1 cells to GEM (P< 0.01), and OSBP2 overexpression increased the resistance of BXPC-3 cells to GEM $(P<0.01)$. (C, D) Increased concentrations of 5-Fu and GEM increased the inhibition of ASPC-1 and BXPC-3 cell lines. OSBP2, oxysterol-binding protein 2; 5-FU, 5 -fluorouracil; GEM, gemcitabine. ${ }^{*} \mathrm{P}<0.05$, ${ }^{\star *} \mathrm{P}<0.01$.

SCID mice. Eight weeks later, the animals were sacrificed, and metastasis progression was monitored. Both lungs were removed for histologic analysis, which revealed that the wet weight of both lungs of mice injected with OSBP2-knockdown ASPC-1 cells was lower than that of mice injected with ASPC-1 cells $(P<0.05$; Figure 7A). The wet weight of both lungs of mice injected with OSBP2-overexpressing BXPC-3 cells was heavier than that of mice injected with BXPC-3 cells $(P<0.05$; Figure 7A). H\&E and OSBP2 staining of randomly selected mouse lung tissues showed that OSBP2 knockdown resulted in lower OSBP2 expression and that OSBP2 overexpression resulted in higher OSBP2 expression in the lung tissues compared to their respective controls (Figures $\mathbf{7 B}, \mathbf{C}$ ).

\section{OSBP2 Promotes EMT in PDAC Cells}

Western blot analysis showed that OSBP2 inhibition led to an increase in E-cadherin expression and a reduction in $\mathrm{N}$-cadherin, vimentin, Snail, $\beta$-catenin, Slug, and ZEB1 expression in ASPC-1 
A
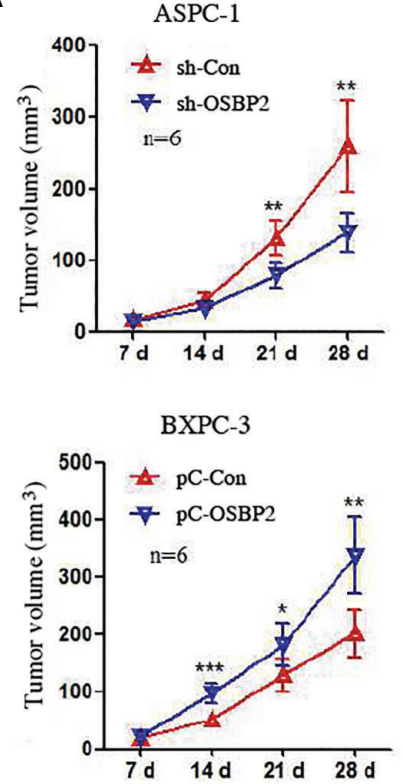

B

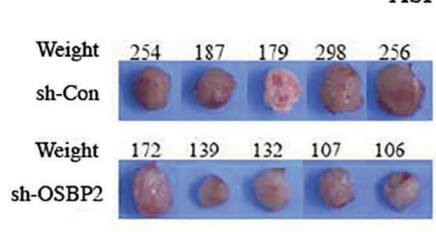

ASPC-1

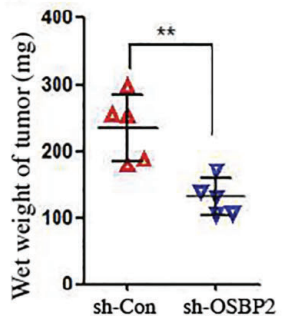

BXPC-3

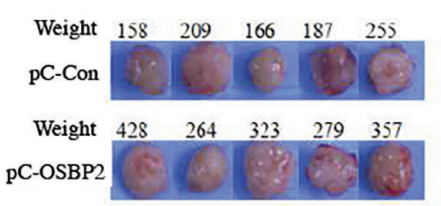

C

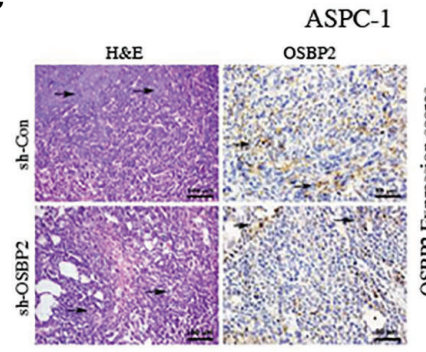

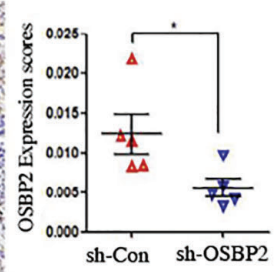

D

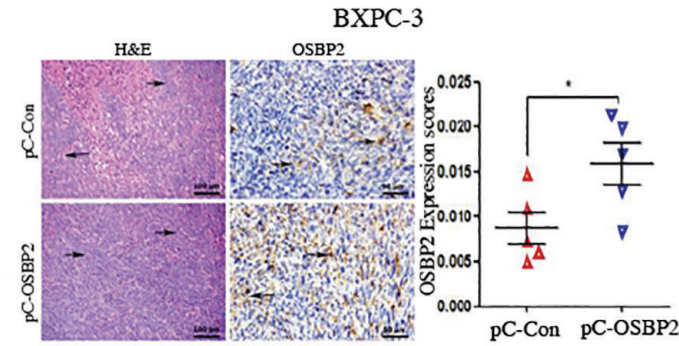

FIGURE 6 | OSBP2 promotes the proliferation of PDAC cells in vivo. (A) OSBP2 knockdown decreased the tumor formation capacity of ASPC-1 cells, and OSBP2 overexpression increased the tumor formation capacity of BXPC-3 cells, as observed in xenograft models. (B) Photographs of excised tumors from nude mice and the tumor weights calculated at the end of the experiment are shown in the right panel. (C, D) Pathologic analysis of tissue sections from recipient mice at 4 weeks post-injection. H\&E (magnification, 200x) and OSBP2 staining (magnification, 200x) were performed. Normalization of OSBP2 expression is shown on the right. OSBP2, oxysterol-binding protein 2; PDAC, pancreatic ductal adenocarcinoma; sh, shRNA; pC, pcDNA3.1 plasmid. ${ }^{*} \mathrm{P}<0.05,{ }^{* *} \mathrm{P}<0.01$.

cells (Figure 8A). By contrast, OSBP2 overexpression resulted in a reduction in E-cadherin expression and an increase in $\mathrm{N}$ cadherin, vimentin, Snail, $\beta$-catenin, Slug, and ZEB1 expression in BXPC-3 cells (Figure 8B). The above results indicated that OSBP2 overexpression promoted the EMT process in PDAC cells.

\section{DISCUSSION}

At present, therapies for managing pancreatic cancer in patients are largely ineffective. PDAC generally predicts a poor prognosis, in part because the symptoms often do not appear obviously until the disease is too advanced for surgical treatment $(2,29,30)$. The major reason for the extremely high mortality rate of PDAC is the invasive and metastatic phenotype of the cancer cells (31), therefore, early detection and intervention remain the greatest challenges in the treatment of this malignancy. Understanding the molecular pathogenesis of PDAC is a mainstream focus of cancer research. In this study, we first demonstrated that OSBP2 could positively promote PDAC cell migration and invasion in vitro and in vivo and that this potentially occurs via EMT.

The domains of OSBPs and ORPs are conserved, namely, high affinity lipid domains that are apt to bind to sterols. These domains of OSBP and ORPs together with the domains of $\mathrm{PH}$ and FFAT participate in sterol/lipid transfer and signal transduction between organelle membranes (32). Diffusion and metastasis are characteristics of malignant tumors. The levels of various OSBPs in tumor cells are different from those in normal cells at the mRNA or protein level, indicating the important role of these proteins in tumorigenesis. ORP inhibitors (named ORPphilins), acting as antiproliferative agents, are crucial for the inhibition of tumor growth and are capable of attenuating 
A

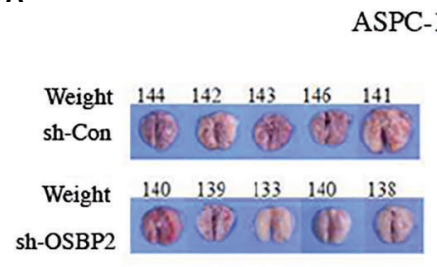

BXPC-3

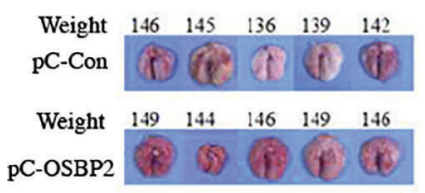

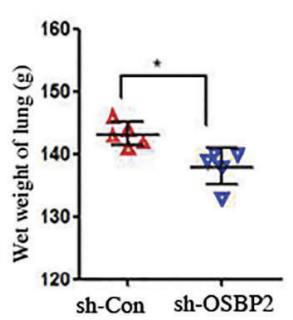

B
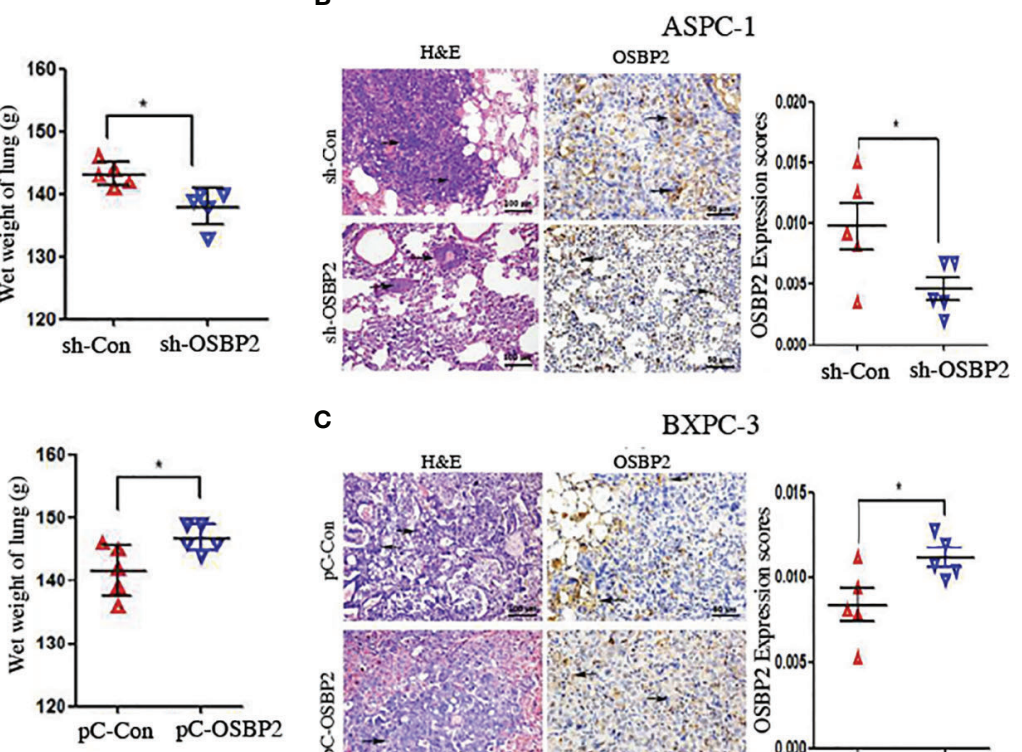

C

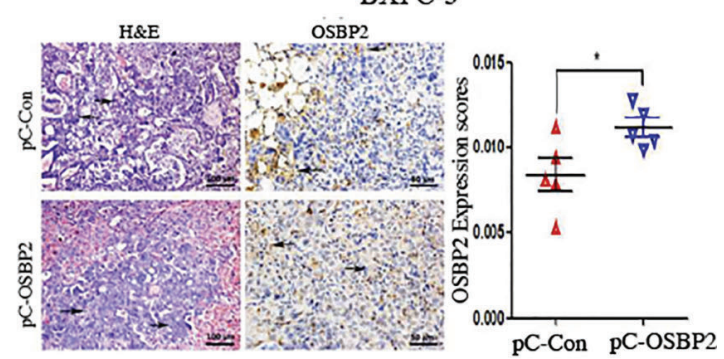

FIGURE 7 | OSBP2 promotes PDAC cell invasion in vivo. (A) Photographs of excised tumors from SCID mice and the lung weights calculated at the end of the experiment. (B, C) Pathologic analysis of tissue sections from recipient mice at 8 weeks post-injection. H\&E (magnification, 200x) and OSBP2 staining (magnification, 200x) were performed. Normalization of OSBP2 expression is shown on the right. OSBP2, oxysterol-binding protein 2; PDAC, pancreatic ductal adenocarcinoma; sh, shRNA; pC, pcDNA3.1 plasmid. *P $<0.05$.

OSBP or ORP4L $(28,33)$. The effects of OSBPs on tumor migration and invasion in various cancer types were revealed by previous studies $(34,35)$. However, there were no data in the literature describing OSBP2 expression and function in pancreatic cancer. In our study, we initially found that OSBP2 was expressed in not only PDAC cell lines but also primary PDAC tissues. The expression of OSBP2 in PDAC tissues was obviously higher than that in paracarcinoma tissues; more importantly, patients with high OSBP2 expression had a worse prognosis, which suggests that OSBP2 could serve as a potential tumor marker for PDAC patients.

PDAC has the lowest 5-year survival rate (8\%) among all tumors, and this rate dwindles to $3 \%$ among individuals initially diagnosed with terminal disease (36). Surgery has an efficacious therapeutic value in this type of cancer, but only $20 \%$ of patients are eligible $(37,38)$. GEM is still the first-line chemotherapeutic for patients who are not eligible for radical resection, and 5-FU is also used as an alternative to GEM, but chemotherapy has limited efficacy for treating metastatic $\operatorname{PDAC}(39,40)$. We first demonstrated that OSBP2 could obviously affect the chemosensitivity of PDAC in patients. When OSBP2 was specifically knocked down, the apoptotic rates of PDAC cells treated with GEM and 5-FU significantly increased. Some research shows that there exists a connection between OSBP family members and malignant tumor cell proliferation and metastasis. Our in vitro and in vivo experiments revealed that OSBP2 not only promotes PDAC cell proliferation but also enhances invasion and metastasis. The abovementioned preliminary results imply that OSBP2 plays a key role in neoplastic progression.

To improve the dismal survival and prognosis of PDAC patients, new effective therapeutic strategies are urgently required. Previous studies have revealed that EMT is responsible for early-stage tumor cell dissemination and is positively involved in the invasion and metastasis of PDAC $(13,41,42)$. Previous work indicated that members of the OSBP family could regulate the subcellular distribution of ORP-VAPA complexes and their impacts on organelle structure and consequently affect malignant tumor cell invasion and metastasis, potentially via changes in vimentin distribution (43). Our research explored the effect of OSBP2 on the phenotypic transformation of PDAC cells by knocking down and overexpressing OSBP2. We demonstrated for the first time that OSBP2 knockdown and overexpression could significantly change the expression of EMT-related markers in PDAC cells. When OSBP2 was knocked down, the levels of the mesenchymal markers $\mathrm{N}$-cadherin and Vimentin and the EMT transcription factors (TFs) $\beta$-catenin, ZEB1, Slug, and Snail were obviously decreased (44). Therefore, we hypothesized that OSBP2 overexpression could be recognized as a potential inducer of EMT.

Diseases with a bleak prognosis urgently need novel therapeutic programs. However, the understanding of tumor biology and taxonomy with regard to PDAC is far from fully elucidated, which can hinder improvements of the treatment effects of available therapies. Here, we provided relevant evidence indicating that OSBP2 is a hallmark of malignancy, offered 
A

B

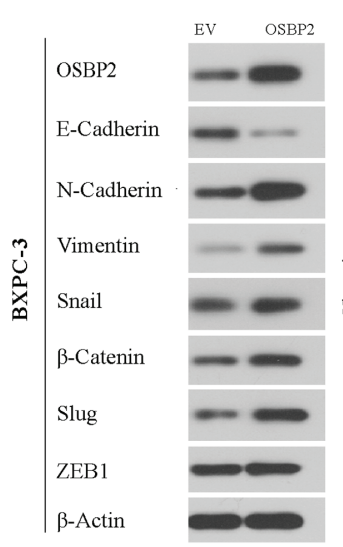

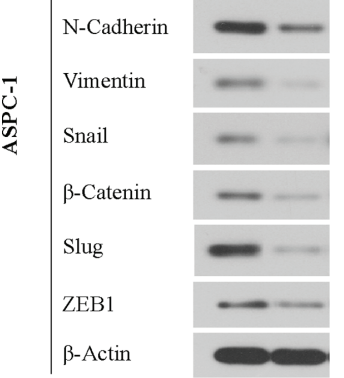
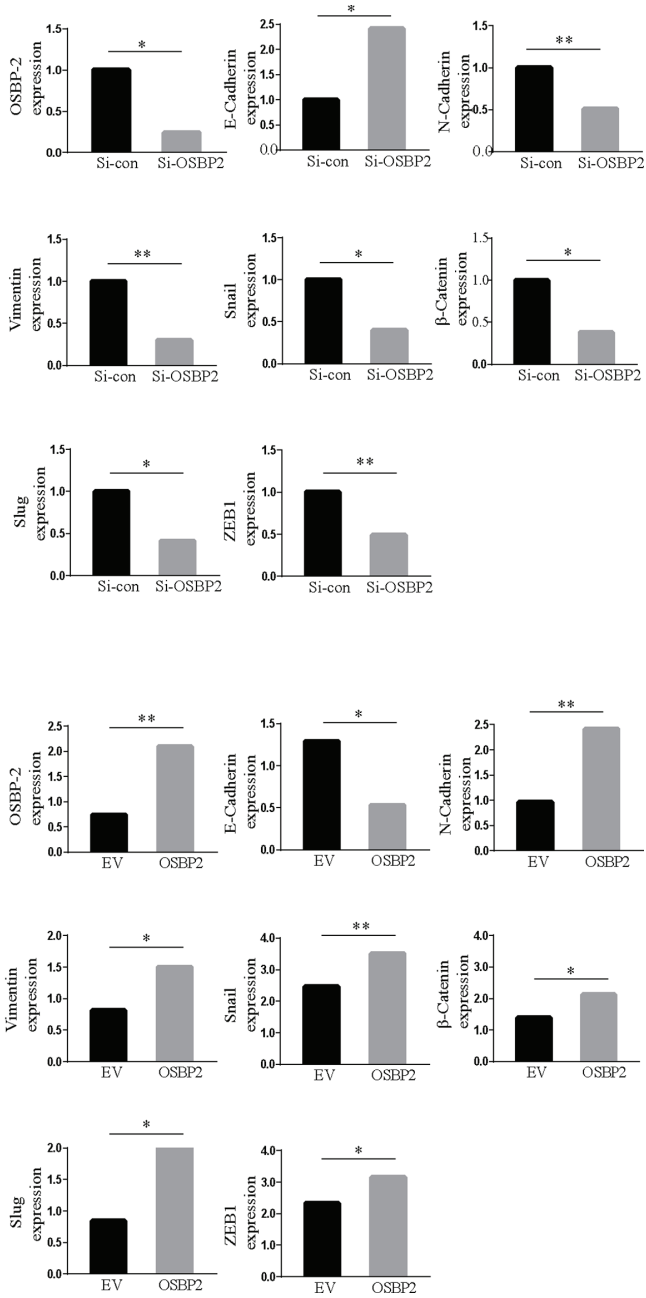

FIGURE 8 | Western blot. (A) Western blot analysis revealed upregulated E-cadherin and downregulated N-cadherin, vimentin, and Snail expression in OSBP2-knockdown ASPC-1 cells. (B) Western blot analysis revealed upregulated N-cadherin, vimentin, and Snail and downregulated E-cadherin expression following overexpression of OSBP2 in BXPC-3 cells. OSBP2, Oxysterol-binding protein $2 .{ }^{*} \mathrm{P}<0.05,{ }^{*} \mathrm{P}<0.01$.

strong data showing that it regulates EMT through novel mechanisms and highlighted its potential as a marker for stratifying pancreatic cancer patient.

\section{DATA AVAILABILITY STATEMENT}

The datasets presented in this study can be found in online repositories. The names of the repository/repositories and accession number(s) can be found in the article/supplementary material.

\section{ETHICS STATEMENT}

The studies involving human participants were reviewed and approved by The Ethics Committee of Scientific Research and Clinical Experiment of the First Affiliated Hospital of Zhengzhou University. The patients/participants provided their written informed consent to participate in this study. The animal study was reviewed and approved by The Ethics Committee of First Affiliated Hospital of Zhengzhou University.

\section{AUTHOR CONTRIBUTIONS}

SH performed experiments, contributed to the analysis and interpretation of the data and was a major contributor in writing the manuscript. $\mathrm{XZ}$ and $\mathrm{KL}$ performed the experiments and contributed to drafting and revising the manuscript. LJ contributed to the data analysis and revision of the manuscript. $\mathrm{RL}$ and JJ contributed to the conception and design of the study, the data analysis and interpretation, and the writing and revision of the manuscript. All authors read and approved the manuscript and agree to be accountable for all aspects of the research in ensuring that the accuracy or integrity of any part of the work are appropriately investigated and resolved. 


\section{FUNDING}

The present study was supported by The Key Scientific Research Project Plan of Henan University (grant no. 20A320037).

\section{REFERENCES}

1. Vincent A, Herman J, Schulick R, Hruban RH, Goggins M. Pancreatic Cancer. Lancet (2011) 378:607-20. doi: 10.1016/S0140-6736(10)62307-0

2. Siegel R, Ma J, Zou Z, Jemal A. Cancer Statistics, 2014. CA Cancer J Clin (2014) 64:9-29. doi: 10.3322/caac.21208

3. German RR, Fink AK, Heron M, Stewart SL, Johnson CJ, Finch JL, et al. The Accuracy of Cancer Mortality Statistics Based on Death Certificates in the United States. Cancer Epidemiol (2011) 35:126-31. doi: 10.1016/j.canep. 2010.09.005

4. Froeling F, Tuveson D. Pancreatic Cancer Foiled by a Switch of Tumour Subtype. Nature (2018) 557:500-1. doi: 10.1038/d41586-018-05129-6

5. Cao J, Yang JC, Ramachandran V, Arumugam T, Deng DF, Li ZS, et al. TM4SF1 Regulates Pancreatic Cancer Migration and Invasion In Vitro and In Vivo. Cell Physiol Biochem (2016) 39:740-50. doi: 10.1159/000445664

6. Waddell N, Pajic M, Patch AM, Chang DK, Kassahn KS, Bailey P, et al. Whole Genomes Redefine the Mutational Landscape of Pancreatic Cancer. Nature (2015) 518:495-501. doi: 10.1038/nature14169

7. Lohr JM. Weighing in on Weight Loss in Pancreatic Cancer. Nature (2018) 558:526-8. doi: 10.1038/d41586-018-05424-2

8. Pommier A, Anaparthy N, Memos N, Kelley ZL, Gouronnec A, Yan R, et al. Unresolved Endoplasmic Reticulum Stress Engenders Immune-Resistant, Latent Pancreatic Cancer Metastases. Science (2018) 360:3602018. doi: 10.1126/science.aao4908

9. Song Z, Feng C, Lu Y, Lin Y, Dong C. PHGDH Is an Independent Prognosis Marker and Contributes Cell Proliferation, Migration and Invasion in Human Pancreatic Cancer. Gene (2018) 642:43-50. doi: 10.1016/j.gene.2017.11.014

10. Jacobetz MA, Chan DS, Neesse A, Bapiro TE, Cook N, Frese KK, et al. Hyaluronan Impairs Vascular Function and Drug Delivery in a Mouse Model of Pancreatic Cancer. Gut (2013) 62:112-20. doi: 10.1136/gutjnl-2012-302529

11. Olive KP, Jacobetz MA, Davidson CJ, Gopinathan A, McIntyre D, Honess D, et al. Inhibition of Hedgehog Signaling Enhances Delivery of Chemotherapy in a Mouse Model of Pancreatic Cancer. Science (2009) 324:1457-61. doi: $10.1126 /$ science. 1171362

12. Provenzano PP, Cuevas C, Chang AE, Goel VK, Von Hoff DD, Hingorani SR. Enzymatic Targeting of the Stroma Ablates Physical Barriers to Treatment of Pancreatic Ductal Adenocarcinoma. Cancer Cell (2012) 21:418-29. doi: 10.1016/j.ccr.2012.01.007

13. Rhim AD, Mirek ET, Aiello NM, Maitra A, Bailey JM, McAllister F, et al. EMT and Dissemination Precede Pancreatic Tumor Formation. Cell (2012) 148:349-61. doi: 10.1016/j.cell.2011.11.025

14. Rasheed ZA, Yang J, Wang Q, Kowalski J, Freed I, Murter C, et al. Prognostic Significance of Tumorigenic Cells With Mesenchymal Features in Pancreatic Adenocarcinoma. J Natl Cancer Inst (2010) 102:340-51. doi: 10.1093/jnci/ djp535

15. Hay ED. An Overview of Epithelio-Mesenchymal Transformation. Acta Anat (Basel) (1995) 154:8-20. doi: 10.1159/000147748

16. Davies JA. Mesenchyme to Epithelium Transition During Development of the Mammalian Kidney Tubule. Acta Anat (Basel) (1996) 156:187-201. doi: $10.1159 / 000147846$

17. Cheng GZ, Chan J, Wang Q, Zhang W, Sun CD, Wang LH. Twist Transcriptionally Up-Regulates AKT2 in Breast Cancer Cells Leading to Increased Migration, Invasion, and Resistance to Paclitaxel. Cancer Res (2007) 67:1979-87. doi: 10.1158/0008-5472.CAN-06-1479

18. Feng H, Zhao X, Guo Q, Feng Y, Ma M, Guo W, et al. Autophagy Resists EMT Process to Maintain Retinal Pigment Epithelium Homeostasis. Int J Biol Sci (2019) 15:507-21. doi: 10.7150/ijbs.30575

19. Pastushenko I, Blanpain C. EMT Transition States During Tumor Progression and Metastasis. Trends Cell Biol (2019) 29:212-26. doi: 10.1016/ j.tcb.2018.12.001

20. Gao S, Sun Y, Zhang X, Hu L, Liu Y, Chua CY, et al. IGFBP2 Activates the NFkappaB Pathway to Drive Epithelial-Mesenchymal Transition and Invasive

\section{ACKNOWLEDGMENTS}

We sincerely express our gratitude to the Laboratory Animal Centre staff of Zhengzhou University.

Character in Pancreatic Ductal Adenocarcinoma. Cancer Res (2016) 76:654354. doi: 10.1158/0008-5472.CAN-16-0438

21. Liu J, Cho YB, Hong HK, Wu S, Ebert PJ, Bray SM, et al. Molecular Dissection of CRC Primary Tumors and Their Matched Liver Metastases Reveals Critical Role of Immune Microenvironment, EMT and Angiogenesis in Cancer Metastasis. Sci Rep (2020) 10:10725. doi: 10.1038/s41598-020-67842-5

22. Morel AP, Hinkal GW, Thomas C, Fauvet F, Courtois-Cox S, Wierinckx A, et al. EMT Inducers Catalyze Malignant Transformation of Mammary Epithelial Cells and Drive Tumorigenesis Towards Claudin-Low Tumors in Transgenic Mice. PLoS Genet (2012) 8:e1002723. doi: 10.1371/ journal.pgen.1002723

23. Hindriksen S, Bijlsma MF. Cancer Stem Cells, EMT, and Developmental Pathway Activation in Pancreatic Tumors. Cancers (Basel) (2012) 4:989-1035. doi: $10.3390 /$ cancers 4040989

24. Liu H, Huang S. Role of Oxysterol-Binding Protein-Related Proteins in Malignant Human Tumours. World J Clin Cases (2020) 8:1-10. doi: 10. 12998/wjcc.v8.i1.1

25. Udagawa O, Ito C, Ogonuki N, Sato H, Lee S, Tripvanuntakul P, et al. OligoAstheno-Teratozoospermia in Mice Lacking ORP4, a Sterol-Binding Protein in the OSBP-Related Protein Family. Genes Cells (2014) 19:13-27. doi: $10.1111 /$ gtc. 12105

26. Fournier MV, Guimaraes da Costa F, Paschoal ME, Ronco LV, Carvalho MG, Pardee AB. Identification of a Gene Encoding a Human Oxysterol-Binding Protein-Homologue: A Potential General Molecular Marker for Blood Dissemination of Solid Tumors. Cancer Res (1999) 59:3748-53.

27. Charman M, Colbourne TR, Pietrangelo A, Kreplak L, Ridgway ND. Oxysterol-Binding Protein (OSBP)-Related Protein 4 (ORP4) is Essential for Cell Proliferation and Survival. J Biol Chem (2014) 289:15705-17. doi: 10.1074/jbc.M114.571216

28. Burgett AW, Poulsen TB, Wangkanont K, Anderson DR, Kikuchi C, Shimada K, et al. Natural Products Reveal Cancer Cell Dependence on OxysterolBinding Proteins. Nat Chem Biol (2011) 7:639-47. doi: 10.1038/nchembio.625

29. Wolfgang CL, Herman JM, Laheru DA, Klein AP, Erdek MA, Fishman EK, et al. Recent Progress in Pancreatic Cancer. CA Cancer J Clin (2013) 63:31848. doi: $10.3322 /$ caac. 21190

30. Stathis A, Moore MJ. Advanced Pancreatic Carcinoma: Current Treatment and Future Challenges. Nat Rev Clin Oncol (2010) 7:163-72. doi: 10.1038/ nrclinonc. 2009.236

31. Cao H, Le D, Yang LX. Current Status in Chemotherapy for Advanced Pancreatic Adenocarcinoma. Anticancer Res (2013) 33:1785-91.

32. Kentala H, Weber-Boyvat M, Olkkonen VM. OSBP-Related Protein Family: Mediators of Lipid Transport and Signaling at Membrane Contact Sites. Int Rev Cell Mol Biol (2016) 321:299-340. doi: 10.1016/bs.ircmb.2015.09.006

33. Weber-Boyvat M, Zhong W, Yan D, Olkkonen VM. Oxysterol-Binding Proteins: Functions in Cell Regulation Beyond Lipid Metabolism. Biochem Pharmacol (2013) 86:89-95. doi: 10.1016/j.bcp.2013.02.016

34. Kovac U, Skubic C, Bohinc L, Rozman D, Rezen T. Oxysterols and Gastrointestinal Cancers Around the Clock. Front Endocrinol (Lausanne) (2019) 10:483. doi: 10.3389/fendo.2019.00483

35. Chen W, Qian X, Hu Y, Jin W, Shan Y, Fang X, et al. SBF-1 Preferentially Inhibits Growth of Highly Malignant Human Liposarcoma Cells. J Pharmacol Sci (2018) 138:271-8. doi: 10.1016/j.jphs.2018.10.009

36. Siegel RL, Miller KD, Jemal A. Cancer Statistics, 2020. CA Cancer J Clin (2020) 70:7-30. doi: 10.3322/caac.21590

37. Kleeff J, Korc M, Apte M, La Vecchia C, Johnson CD, Biankin AV, et al. Pancreatic Cancer. Nat Rev Dis Primers (2016) 2:16022. doi: 10.1038/ nrdp. 2016.22

38. Kamarajah SK, Bundred JR, Alrawashdeh W, Manas D, White SA. A Systematic Review and Network Meta-Analysis of Phase III Randomised Controlled Trials for Adjuvant Therapy Following Resection of Pancreatic Ductal Adenocarcinoma (PDAC). HPB (Oxford) (2020) 22:649-59. doi: 10.1016/j.hpb.2019.12.001 
39. Lin KI, Yang JL, Lin YC, Chou CY, Chen JH, Hung CC. Network MetaAnalysis of Efficacy and Safety of Chemotherapy and Target Therapy in the First-Line Setting of Advanced Pancreatic Cancer. Cancers (Basel) (2019) 11:112019. doi: 10.3390/cancers11111746

40. Oneda E, Zaniboni A. Are We Sure That Adjuvant Chemotherapy Is the Best Approach for Resectable Pancreatic Cancer? Are We in the Era of Neoadjuvant Treatment? A Review of Current Literature. J Clin Med (2019) 8:82019. doi: $10.3390 / j \mathrm{~cm} 8111922$

41. Hotz B, Arndt M, Dullat S, Bhargava S, Buhr HJ, Hotz HG. Epithelial to Mesenchymal Transition: Expression of the Regulators Snail, Slug, and Twist in Pancreatic Cancer. Clin Cancer Res (2007) 13:4769-76. doi: 10.1158/1078-0432.CCR-06-2926

42. Arumugam T, Ramachandran V, Fournier KF, Wang H, Marquis L, Abbruzzese JL, et al. Epithelial to Mesenchymal Transition Contributes to Drug Resistance in Pancreatic Cancer. Cancer Res (2009) 69:5820-8. doi: 10.1158/0008-5472.CAN-08-2819

43. Kentala H, Pfisterer SG, Olkkonen VM, Weber-Boyvat M. Sterol Liganding of OSBP-Related Proteins (ORPs) Regulates the Subcellular Distribution of ORP-VAPA Complexes and Their Impacts on Organelle Structure. Steroids (2015) 99:248-58. doi: 10.1016/j.steroids.2015.01.027

44. Galvan JA, Zlobec I, Wartenberg M, Lugli A, Gloor B, Perren A, et al. Expression of E-Cadherin Repressors SNAIL, ZEB1 and ZEB2 by Tumour and
Stromal Cells Influences Tumour-Budding Phenotype and Suggests Heterogeneity of Stromal Cells in Pancreatic Cancer. Br J Cancer (2015) 112:1944-50. doi: 10.1038/bjc.2015.177

Conflict of Interest: The authors declare that the research was conducted in the absence of any commercial or financial relationships that could be construed as a potential conflict of interest.

Publisher's Note: All claims expressed in this article are solely those of the authors and do not necessarily represent those of their affiliated organizations, or those of the publisher, the editors and the reviewers. Any product that may be evaluated in this article, or claim that may be made by its manufacturer, is not guaranteed or endorsed by the publisher.

Copyright (C) 2022 Huang, Zhang, Luo, Jiang, Jiang and Li. This is an open-access article distributed under the terms of the Creative Commons Attribution License (CC BY). The use, distribution or reproduction in other forums is permitted, provided the original author(s) and the copyright owner(s) are credited and that the original publication in this journal is cited, in accordance with accepted academic practice. No use, distribution or reproduction is permitted which does not comply with these terms. 